\title{
LEVANTAMENTO DA OPINIÃO DOS ACADÊMICOS DE CIÊNCIAS BIOLÓGICAS DE GOIÂNIA SOBRE GENÉTICA APLICADA À MEDICINA
}

\author{
Aroldo Vieira de MORAES FILHO ${ }^{*}$ \\ Leliane Viégas MUNIZ² \\ Mônica Santiago BARBOSA ${ }^{3}$
}

\begin{abstract}
${ }^{1}$ Cursista da Especialização em Tecnologias aplicadas ao Ensino de Biologia, Universidade Federal de Goiás, Goiânia, Brasil. E-mail: moraesfilho18a@hotmail.com

2 Profa. da rede particular e municipal de Ensino Fundamental e Médio, Especialista em Biologia Geral. E-mail: lelianebio@hotmail.com

3 Profa. Dra. Orientadora da Especialização em Tecnologias aplicadas ao Ensino de Biologia, Universidade Federal de Goiás, Goiânia, Brasil. E-mail: santiagosant@gmail.com
\end{abstract}

Recebido em: 29/10/2013 - Aprovado em: 22/12/2013 - Disponibilizado em: 15/01/2014

RESUMO: Com o desenvolvimento acelerado das técnicas genéticas, emergem novas polêmicas que exigem o conhecimento aprofundado da ética aplicada. Entre os dilemas que permeiam o desenvolvimento da Genética, podemos citar a Genética Médica (dedicada às pessoas com doenças hereditárias) e a Investigação Genética (que centra os estudos no mapeamento do genoma humano). Portanto, o objetivo deste trabalho foi realizar, por meio da aplicação de questionários, o levantamento das opiniões dos acadêmicos do curso de Ciências Biológicas (modalidade presencial) de todas as universidades de Goiânia - GO a respeito dos avanços genéticos. Além disso, investigou-se discentes que cursaram a disciplina de Genética e os discentes que ainda não cursaram essa disciplina no intuito de verificar se o conhecimento mais aprofundado a respeito do tema em questão influenciava a opinião dos participantes. Nesta pesquisa, a maioria dos participantes apoia a aplicação dos avanços da genética, pois as respostas a favor da ciência foram mais frequentes do que as respostas a favor da religião em todas as questões. Além disso, foi possível observar que o conhecimento a respeito desses avanços interfere nas opiniões dos acadêmicos, porque na maioria das questões as respostas dos graduandos que cursaram a disciplina de Genética e, assinalaram as opções que remetem aos avanços da ciência, foram mais significativas em relação aos alunos que não cursaram essa disciplina.

Palavras-chave: Genética. Ética. Estudantes. Opinião. Questionário.

ABSTRACT: With the rapid development of genetic techniques, new controversies emerge that require the detailed knowledge of applied ethics. Among the dilemmas that underlie the development of genetics, we can cite the Medical Genetics (dedicated to people with hereditary diseases) and Genetic Research (studies that focuses on the mapping of the human genome). Therefore, the aim of this study was, by means of questionnaires, classify the opinions of students of Biological Sciences (classroom mode) of all universities in Goiania-GO about genetic advances. Furthermore, we investigated students in the discipline of Genetics and students who have not attended this course in order to verify that the deeper knowledge about the subject in question influenced participants' perceptions. In this research, the majority of participants supported the application of advances in genetics, since the responses in favor of science were more frequent than the responses in favor of religion in all matters. Furthermore, it was observed that knowledge about these advances affect the opinions of academics, because most of the questions the answers of the students in the discipline of Genetics and pointed the options that lead to advances in science, were more significant in compared to students who did not attend this course.

Keywords: Genetics. Ethics. Students. Opinion. Questionnaire. 


\section{INTRODUÇÃO:}

As técnicas de biologia molecular e genética permitem a identificação precoce de determinadas doenças, a detecção de susceptibilidade a doenças genéticas e avaliação do grau de exposição a agentes exógenos, facilitando a prevenção de doenças graves (WÜNSCH FILHO; GATTÁS, 2001).

Para Diaféria (2002), com a utilização de técnicas modernas e sofisticadas, o homem tornou-se capaz de interferir nos processos naturais dos sistemas biológicos, porque podem transformar ou criar novos organismos por meio de pequenas estruturas moleculares ou do material genético, alterando assim a dinâmica da história humana.

A sociedade tem se atentado aos avanços da ciência, pois a mesma pode possuir um potencial devastador, como foi provado pela física (bombas atômicas, por exemplo). Por isso, a orientação responsável do comportamento humano no momento da produção e da aplicação do conhecimento é muito relevante para garantir às futuras gerações, condições necessárias para ter uma vida digna (MINARÉ, 2002).

Por outro lado, desde o início da civilização a espécie humana busca a imortalidade e a "saúde perfeita" e as discussões da sobre clonagem e outras técnicas genéticas inserem-se nesse contexto. Cabe a todos os envolvidos nessas pesquisas transmitir informações necessárias para desconstruir argumentos sobre a demonização dessas técnicas. Porém, seja por razões de insegurança técnica, de poucos esclarecimentos dos aspectos morais ou pela própria evolução da pesquisa é que foram criadas essa polarização da genética entre endeusamento ou demonização (GARRAFA, 2002).

Com o desenvolvimento acelerado dessas técnicas genéticas, emergem novas polêmicas que exigem o conhecimento aprofundado da ética aplicada, pois a bioética consiste do estudo sistemático das dimensões morais no campo das ciências da vida e do cuidado da saúde, com o objetivo de auxiliar o homem a resolver os desafios que surgem com os avanços da Ciência. Entre os dilemas que permeiam o desenvolvimento da Genética, podemos citar a Genética Médica (dedicada às pessoas com doenças hereditárias) e a Investigação Genética (que centra os estudos no mapeamento do genoma humano) (BETANCOURT, 2007).

Com o intuito de preparar um país com pessoas mais críticas e responsáveis para participar ativamente de debates científicos e auxiliar na melhoria intelectual da população, deve haver por parte da comunidade científica e dos responsáveis por meios de comunicação, maiores preocupações em manter a sociedade informada acerca dos avanços biotecnológicos. Além disso, pesquisadores e a sociedade devem manter-se 
unidos em relação às reflexões relacionadas aos avanços genéticos, visto que estes testes estão sendo amplamente utilizados na saúde pública. Disseminar informações que suscitem o diagnóstico e o tratamento precoce e implantar uma política de saúde pública que amplie o acesso a especialistas em genética é hoje o grande desafio da área (MORAES FILHO et al., 2013).

Portanto, o objetivo deste trabalho foi realizar o levantamento das opiniões dos acadêmicos do curso de Ciências Biológicas (modalidade presencial) de todas as universidades de Goiânia - GO a respeito dos avanços genéticos. Além disso, investigou-se discentes que cursaram a disciplina de Genética e os discentes que ainda não cursaram essa disciplina, no intuito de verificar se o conhecimento mais aprofundado a respeito do tema em questão influenciava a opinião dos participantes.

\section{MATERIAL E MÉTODOS:}

A coleta de dados foi realizada por meio de questionários auto-preenchíveis, elaborado por Moraes Filho et al. (2013), com perguntas objetivas, que foram aplicados aos discentes de duas turmas de cada Instituição de Ensino Superior (IES) que oferecem os cursos de Ciências Biológicas (modalidade presencial) em Goiânia, sendo uma turma que não cursou a disciplina de Genética e outra turma que já cursou disciplina, para comparar se as opiniões poderiam ser alteradas conforme o conhecimento sobre o assunto tratado.

Houve uma prévia autorização dos coordenadores dos cursos por meio da assinatura do Termo de Consentimento para a participação dos educandos na pesquisa.

Após uma explicação sobre a pesquisa para cada turma, o questionário foi distribuído aleatoriamente e aplicado pelo pesquisador durante as aulas, levando em consideração a voluntariedade e a assinatura do Termo de Consentimento Livre e Esclarecido como fator determinante para a participação.

Os conceitos estão explicados nos enunciados, pois segundo Faerstein et al. (1999), durante a elaboração de questionários deve-se minimizar possíveis dificuldades de compreensão do texto das perguntas e das opções de respostas.

As respostas foram representadas por meio de gráficos e tabelas, utilizando-se da abordagem quantitativa para complementação/representação dos dados.

\section{RESULTADOS E DISCUSSÃO:}

Participaram da pesquisa, 120 universitários (70\% do sexo feminino e $30 \%$ masculino) que ainda não cursaram a disciplina de Genética e 120 (70,83\% do sexo feminino e $29,17 \%$ masculino) que cursaram essa disciplina. Os participantes possuíam entre 17 e 47 anos.

Quando indagados sobre se considerarem criacionistas ou evolucionistas, dos 
acadêmicos que não cursaram Genética 17,5\%

consideram-se criacionistas, $31,67 \%$ evolucionistas, $8,33 \%$ não são nem criacionistas e nem evolucionistas e $42,5 \%$ não tem uma opinião formada sobre 0 assunto. Por outro lado, dos graduandos que cursaram a disciplina de Genética 28,33\% disseram ser criacionistas, $41,67 \%$ evolucionistas, $9,17 \%$ nenhum dos dois e $20,83 \%$ não tem uma opinião formada sobre o assunto.

Em relação à responsabilidade de divulgação científica sobre os avanços da genética, dos participantes que não cursaram Genética $15 \%$ acreditam ser da mídia essa responsabilidade, $24,17 \%$ do governo, 54,16 $\%$ dos pesquisadores e $6,67 \%$ acreditam ser outros setores da sociedade os responsáveis por essa divulgação. Para os discentes que cursaram Genética, 7,5\% assinalaram a mídia como a principal responsável pela divulgação científica, 37,5\% acreditam que é o governo, $50 \%$ afirmaram que são os pesquisadores e $5 \%$ apontam que são outros setores da sociedade.

Para $11,67 \%$ dos pesquisados que ainda não cursaram Genética, o principal meio de divulgação científica deve ser a televisão, para $13,33 \%$ a internet, $67,5 \%$ acreditam que devem ser os periódicos (jornais, revistas e boletins) e 7,5\% assinalaram que são outros os principais meios de divulgação científica. Quando a mesma pergunta foi realizada para os acadêmicos que cursaram a disciplina
$4,17 \%$ assinalaram a televisão, $13,33 \%$ a internet, $73,33 \%$ os periódicos e $9,17 \%$ outros meios.

Em nossos resultados, a maioria dos participantes acredita que a responsabilidade da divulgação dos avanços científicos é dos pesquisadores por meio de periódicos. No entanto, segundo Brito Filho e Dias (2002) a sociedade necessita de esclarecimento adequado por meio de informações científicas, mas para atingir esse objetivo é fundamental o papel da imprensa, do jornalismo científico, dos representantes das leis para facilitar a discussão plena das ferramentas genéticas pela sociedade.

Os dados referentes às perguntas que envolvem as técnicas genéticas tanto para os alunos que cursaram Genética quanto para os que não cursaram encontram-se representados na Tabela 1.

Nossos resultados corroboram com um estudo conduzido por Moraes Filho et al. (2013) com discentes e docentes de Instituições de Ensino Superior (IES) no Estado de Goiás, em relação aos avanços na área da Genética, os resultados mostraram que a maioria dos participantes acreditam que as ferramentas genéticas devem ser utilizadas, fazendo o possível para melhorar a qualidade de vida e que o fato da pessoa saber com antecedência se possui predisposições a doenças genéticas graves é benéfico.

Lima et al. (2010) investigaram, no município de Morrinhos, os avanços da 
engenharia genética, abordando principalmente o Projeto Genoma Humano (PGH) e, os participantes demonstraram pouco conhecimento a respeito do assunto, porém, em contrapartida, demonstraram interesse em conhecer mais a respeito desse avanço genético.

Em outra pesquisa realizada em Morrinhos-GO a maioria dos participantes afirmaram que aceitam os estudos com células-tronco embrionárias humanas, o descarte de embriões e a clonagem (FERREIRA et al., 2007). Outra pesquisa realizada no mesmo município, os universitários da Universidade Estadual de Goiás - Unidade Universitária de Morrinhos (UEG-UnU de Morrinhos) afirmaram apoiar o uso de células-tronco para fins científicos (ROCHA et al., 2007). Quando os estudantes de escolas públicas e particulares de Morrinhos - GO foram indagados a respeito das células-tronco, os mesmos demonstraram conhecer sobre o assunto e as polêmicas sociais inerentes ao tema em questão (MACEDO et al., 2007).

Nessa pesquisa a maioria dos participantes afirmou que o diagnóstico genético pré-implantatório é favorável porque todos os pais desejam o melhor para seus filhos, contradizendo os dados obtidos na pesquisa de Moraes Filho et al. (2013), pois a maioria dos participantes acreditaram que esse diagnóstico é desfavorável porque o filho é um dom de Deus. Em relação às outras técnicas todos os dados corroboram com o estudo de Moraes Filho et al. (2013) realizado com o mesmo questionário aplicado em discentes e docentes de Educação Física, Farmácia e Ciências Biológicas das Instituições de Ensino Superior no Estado de Goiás.

Portanto, de acordo com os nossos resultados e as pesquisas citadas acima, tanto os estudantes como a população em geral demonstram interesse em conhecer os avanços genéticos com o intuito de esclarecer algumas dúvidas e preocupações éticas e morais inerentes da aplicação dessas técnicas na área da saúde.

\section{CONCLUSÃO}

Nesta pesquisa, a maioria dos participantes apoia a aplicação dos avanços da genética, pois as respostas a favor da ciência foram mais frequentes do que as respostas a favor da religião em todas as questões. Além disso, podemos concluir que o conhecimento a respeito desses avanços interfere nas opiniões dos acadêmicos, porque na maioria das questões as respostas dos graduandos que cursaram a disciplina de Genética e, assinalaram as opções que remetem aos avanços da ciência, foi mais significativo em relação aos alunos que não cursaram essa disciplina.

Além disso, essa pesquisa de opinião a respeito dos avanços da genética é de suma 
importância, pelo fato de demonstrar o posicionamento dos futuros biólogos sobre a aplicação dessas ferramentas científicas, pois os avanços da ciência devem ser bem discutidos, principalmente no que tange os conceitos éticos e legais da sua utilização. 
Tabela 1. Porcentagem dos questionados em relação a genética aplicada a medicina

\begin{tabular}{|c|c|c|}
\hline \multirow[b]{2}{*}{ Perguntas } & \multicolumn{2}{|c|}{ Respostas em porcentagem (\%) } \\
\hline & Acadêmicos que não cursaram Genética & Acadêmicos que cursaram Genética \\
\hline \multicolumn{3}{|l|}{ A fertilização in vitro: } \\
\hline $\begin{array}{l}\text { a) Deve ser aceita, pois realiza o desejo e decisão do } \\
\text { casal em ter um filho; }\end{array}$ & 74,17 & 74,17 \\
\hline $\begin{array}{l}\text { b) Deve ser rejeitada, pois a vida brota das mãos de } \\
\text { Deus; }\end{array}$ & 1,67 & 0,83 \\
\hline $\begin{array}{l}\text { c) Depende do caso, pois a vida humana é uma } \\
\text { realidade ética e religiosa; }\end{array}$ & 20,83 & 23,33 \\
\hline d) Outros; & 3,33 & 1,67 \\
\hline \multicolumn{3}{|l|}{ A clonagem terapêutica: } \\
\hline $\begin{array}{l}\text { a) É negativa, pois o embrião tem vida e merece todo o } \\
\text { respeito; }\end{array}$ & 22,5 & 17,5 \\
\hline $\begin{array}{l}\text { b) É positiva, desde que seja para a melhoria das } \\
\text { condições de saúde e sobrevivência humana; }\end{array}$ & 73,34 & 72,5 \\
\hline c) É negativa, pois a vida humana é um ato divino; & 3,33 & 5,83 \\
\hline d) Outros; & 0,83 & 4,17 \\
\hline O diagnóstico genético pré-implantatório: & & \\
\hline
\end{tabular}

a) É desfavorável porque o filho será amado por ter 
b) É favorável porque todos os pais desejam o melhor

c) É desfavorável porque o filho é um dom de Deus;

30,83

d) Outros;

6,67

11,67

A utilização de plantas transgênicas:

a)É benéfica, pois elas são mais produtivas e resistentes;

b)É maléfica, pois esses produtos não são confiáveis;

c) É maléfica, pois tem risco de hibridização de espécies nativas com plantas transgênicas;

10,83

d) Outros;

4,17

Acredita que a engenharia genética:

a)Tem o direito de fazer o possível para melhorar a qualidade de vida, aperfeiçoando e eliminando características;

b)Não tem o direito de intervir na vida, pois somente Deus tem o domínio sobre ela;

c)Não tem o direito de modificar as características dos seres pois a manipulação dos genes é irreversível;

d)Outros; 


\section{Saber com antecedência se tem predisposição a}

doenças graves:

a)É positivo, pois a pessoa pode modificar seus hábitos a tempo;

c)É negativo, pois abala o psicológico da pessoa e acelera o desenvolvimento patogênico;

d)Outros;

Acredita que o exame genético:

b)Deve ser realizado quando o paciente desejar saber sobre a sua predisposição genética;

c)Nunca deve ser realizado;

Acredita que a criação de um banco de dados:

a) É positiva, pois auxilia a descoberta de criminosos mais rápido, agilizando a justiça brasileira;

b)É negativa, pois não se deve obrigar ninguém a doar seu material genético para o banco de dados; 
c)É negativa, pois indiretamente expõe a vida da pessoa, gerando discriminação;

d)Outros;

Fonte: produção do próprio autor 


\section{REFERÊNCIAS}

BETANCOURT, I. A. R. Bioética y genética. Rev. Cubana Genet. Comunit. v.1, n.1, p.9-14, 2007.

DIAFÉRIA, A.; Código de ética de manipulação genética: alcance e interface com regulamentações correlatas. Parcerias estratégicas, n. 16, 2002.

BRITO FILHO, M. T.; DIAS, E. P. F. A bioética nos processos biotecnológicos. Parcerias estratégicas, n. 16, 2002.

FAERSTEIN , E.; LOPES, C. S.; VALENTE, K.; PLÁ, M. A. S.; FERREIRA, M. B. Pré-testes de um questionário multidimensional autopreenchível: a experiência do estudo pró-saúde UERJ. Rev. Saúde

Coletiva.v.9, n.2, p.117-130, 1999.

FERREIRA, G. M.; LIMA, J. P. R.; PAIS, L. P. P.; RODRIGUES, R. A.; PIRES, D. J. A influência da religião em relação à atuais pesquisas sobre células-tronco, em Morrinhos - GO. In: SEMANA DE INICIAÇÃO CIENTÍFICA DA UEG UNU MORRINHOS, 5, 2007. Morrinhos GO. Anais da IV \& V Semana de Iniciação Cientifica da UEG UnU Morrinhos: (CDROM), 2007.

GARRAFA, V. Crítica bioética a um nascimento anunciado. Parcerias estratégicas, n. 16, 2002.

LIMA, N. K. P.; VAZ, A. P. A.; QUEIROZ, C. E. B.; ARAÚJO, F. S.; REGIS, K. G. Avaliação do conhecimento social no município de Morrinhos - GO a respeito do Projeto Genoma Humano.

Revista Movimenta. v.3, n.4, p.163-167, 2010.

MACEDO, D. J.; MACÊDO, M. S.; RIBEIRO, A. I.; SILVA, E. M.; PIRES, D. J. Avaliação do conhecimento dos alunos do ensino médio de escolas: particular, pública e EJA do município de Morrinhos (GO) sobre células-tronco. In: SEMANA DE INICIAÇÃO CIENTÍFICA DA UEG - UNU MORRINHOS, 5, 2007. Morrinhos - GO. Anais da IV \& V Semana de Iniciação Cientifica da UEG UnU Morrinhos: (CDROM), 2007.

MINARÉ, R. L. Bioética. Parcerias estratégicas, n. 16, 2002.

MORAES FILHO, A. V.; MELO, W. A.; PRAZERES, P. A.; PESQUERO, M. F.; PARREIRA, I. A. R.; PIRES, D. J.

Engenharia Genética: uma avaliação das opiniões de discentes e docentes de instituições de ensino superior no Estado de Goiás. Revista Eletrônica de Educação da Faculdade Araguaia RENEFARA, v. 4, p. 206-221, 2013.

ROCHA, L. H. O.; SILVA, D. R.; NOGUEIRA, A. C.; MORAIS, L. R. P.; FERREIRA, L. V.; PIRES, D. J.

Conhecimento e opiniões dos discentes de cinco cursos regulares da UEG Morrinhos sobre células-tronco. In: SEMANA DE INICIAÇÃO CIENTÍFICA DA UEG - UNU MORRINHOS, 5, 2007. Morrinhos - GO. Anais da IV \& V Semana de Iniciação Cientifica da UEG UnU Morrinhos: (CD-ROM), 2007.

WÜNSCH FILHO, V.; GATTÁS, G. J. F. Biomarcadores moleculares em câncer. Cadernos de Saúde Pública. v.17, p.467480, 2001. 